\title{
Commentary
}

\section{Revisiting the Environmental Kuznets Curve: The Spatial Interaction between Economy and Territory}

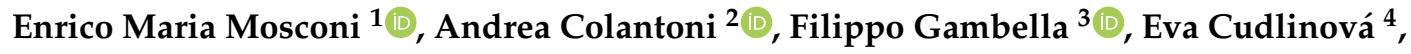 \\ Luca Salvati ${ }^{5, *}$ and Jesús Rodrigo-Comino ${ }^{6,7}$ \\ 1 Department of Economics, Engeneering, Society and Business, University of Tuscia, Via del Paradiso 47, \\ I-01100 Viterbo, Italy; enrico.mosconi@unitus.it \\ 2 Department of Agricultural and Forest Science, University of Tuscia, Via S. Camillo de Lellis snc, \\ I-01100 Viterbo, Italy; colantoni@unitus.it \\ 3 Department of Agricultural Science, University of Sassari, Viale Italia 39, I-07100 Sassari, Italy; \\ gambella@uniss.it \\ 4 Department of Regional Management, Faculty of Economics, University of South Bohemia in České \\ Budějovice, 13 CZ-37005 Studentská, Czech Republic; evacu@centrum.cz \\ 5 Department of Economics and Law, University of Macerata, Via Armaroli 43, I-62100 Macerata, Italy \\ 6 Physical Geography, Trier University, 54286 Trier, Germany; jesus.rodrigo@uv.es \\ 7 Soil Erosion and Degradation Research Group, Department of Geography, University of Valencia, \\ 46010 Valencia, Spain \\ * Correspondence: luca.salvati@unimc.it; Tel.: +39-380-72-89-966
}

Received: 17 July 2020; Accepted: 2 September 2020; Published: 14 September 2020

\begin{abstract}
A complex interplay of socio-ecological drivers of change exists at the different spatiotemporal scales affecting environmental degradation. This is a key issue worldwide and needs to be understood to develop efficient management solutions. One of the most applied theories in the regional analysis is the U-shaped relationship between environmental degradation and the level of income in a given economic system or Environmental Kuznets Curve (EKC). Specifically, the EKC hypothesis underlines the (potentially positive) role of formal responses to environmental degradation grounded on government policies that are usually more ambitious in wealthier economic systems. However, there is a lack of knowledge on the role of space in EKC, arguing that spatial variability in the environment-income relationship may indicate additional targets for integrated socio-environmental policies. We hypothesize that a spatially differentiated response to environmental degradation could better adapt to differentiated local contexts. Therefore, to achieve this goal, we present a multi-scale investigation of degradation processes at the local level, providing a refined knowledge of the environment-economy linkages considering more traditional, cross-country and cross-region exercises. Our results demonstrated that-together with temporal, sectoral, and institutional aspects—space and, consequently, the related analysis' spatial scales, are significant dimensions in ecological economics, whose investigation requires improvements in data collection and dedicated statistical approaches.
\end{abstract}

Keywords: space; scale; land degradation; externalities; indicators; Italy

JEL Classification: Q5; R10; R14

\section{Introduction}

Social inequality, economic polarization, and territorial disparities represent a challenge in sustainable development, with direct (and indirect) environmental impacts (Boyce 1994; Barrett and Graddy 2000; Heerink et al. 2001). Environmental degradation has been observed in both 
emerging economies and wealthier countries and exerts an increasing impact on natural ecosystem functioning and services (Sannigrahi et al. 2020; Sannigrahi et al. 2019). Several countries have shown accelerated rates of economic growth over the last decades; however, a sustained expansion seems to be no longer replicable under business-as-usual socio-ecological contexts (Fingleton 2016). It was, therefore, questioned whether a persistent growth-under policy inaction-is a sufficient condition to contain the pressure of human activities on the environment (Kahuthu 2006). Nowadays, we are assisting in a progressive 'globalization' of ecological degradation issues, while missing the socio-environmental role of both 'regional' and 'local' dimensions contributing to such processes (Briassoulis 2005). This would reflect the multifaceted interactions among economic dynamics, local communities and the ecological systems experiencing increased human disturbances (Franceschi and Kahn 2003; Dasgupta et al. 2006). Specific or combined biophysical and socio-economic drivers can cause environmental degradation affecting advanced and emerging economies with different intensity and severity (Cavlovic et al. 2000). Therefore, a refined understanding of the most significant factors fuelling economic growth and environmental measures is key to developing a more effective and coordinated response to ecosystem degradation (List and Gallet 1999) and achieving land degradation neutrality (Akhtar-Schuster et al. 2017). While countries have shown marked growth rates over the last century, a continued economic expansion-without policy intervention-is no longer regarded as a sufficient condition to contain human impacts (Agras and Chapman 1999). In such contexts, Spangenberg (Spangenberg 2001) outlined the importance of negative environmental externalities of the economic systems.

As a consequence, theoretical frameworks and quantitative approaches assessing convergence (or divergence) between economic growth and ecosystem degradation have been developed (Mukherjee and Kathuria 2006). In this regard, the Environmental Kuznets Curve (EKC) hypothesizing the existence of a non-linear, inverted U-shaped relationship between ecosystem degradation and a country's income, has attracted increasing interest among scholars, policy-makers, and stakeholders (Caviglia-Harris et al. 2009). This hypothesis assumes the (supposedly beneficial) indirect role of rising income in maintaining ecosystem functions (Dasgupta et al. 2006). This assumption has contributed to broaden positive and normative debates on the environment-economy relationship while receiving criticism (Smulders 1999). However, the importance of the 'spatial' dimension in EKC research, as opposed to other relevant dimensions investigated in earlier studies (e.g., time, economic specialization, governance form, socio-cultural background), was usually missed. A renewed debate about which role (i) space and (ii) spatial scales play in the Environmental Kuznets Curve is still pending.

Suggesting a multi-scale analysis of degradation processes with high resolution and large spatial coverage (e.g., at local administrative-ecological territorial units) would allow a refined understanding of the largely differentiated environment-economy relationships over space (Auffhammer and Carson 2008). The spatial variability in the environment-economy relationship was assumed to reflect a locally specific role of income, wealth, and other socio-economic characteristics with differentiated linkages depending on the background context (Dinda 2004). Multi-scale investigations of the environment-economy dynamics oriented toward the EKC assumption may outline additional targets for integrated socio-ecological policies, with respect to more traditional, cross-country exercises (Stern 2004). Rupasingha et al. (Rupasingha et al. 2004) analyzed the relationship between per-capita income and toxic pollutants across 3029 continental United States counties, the most detailed spatial level for which used data can be found, and introduced refinements to address many of the worrisome aspects of the economy-environment relation. By demonstrating the awareness of most aspects highlighted here and related to the lack of information about this topic, a novel interpretation of the role of 'space' was proposed by estimating a spatial-lag statistical model (Rupasingha et al. 2004) and discussing the possible 'scale mismatch' among data used in environmental research.

Anselin (Anselin 2001a, 2001b) stated that environmental characteristics are often derived from physical measurements that result from an underlying spatial sampling design, and neither economic nor physical data collections necessarily match the spatial scale of the phenomenon under study. 
Reflecting non-stationary and spatially heterogeneous environmental, social and economic processes interacting at multiple geographical scales, these (local-based) relationships require specific policy approaches with responses modulated at different (administrative) spatial domains. Being considered a sort of early warning predictor for intensity and severity of ecological degradation, local response to differentiated environmental-economy relationships should be flexible enough to adapt to transforming socio-economic contexts. However, a research gap still exists when linking (individual) processes of ecological degradation varying largely over space and the local background context in light of the EKC hypothesis (Salvati and Carlucci 2010). Substantive and methodological issues (with both positive and normative implications) remain at the base of this relationship (Salvati 2016): examples include the most appropriate size of spatial units to study the interactions between each process (e.g., environmental degradation and economic development).

By discussing the importance of a better understanding of local relationships between environment and income, the present commentary aims at (i) introducing some operational definitions of the Environmental Kuznets Curve; (ii) illustrating the main strengths and weaknesses of the EKC assumption; (iii) broadening the debate on the EKC through a specific focus on spatial and scaling issues; and (iv) evidencing the take-home message of this contribution, proposing a refined understanding of the spatially differentiated environment-economy nexus applied to a specific case study. By focusing on the importance of spatial explicit local approaches to EKC (Salvati and Zitti 2005), this paper (i) highlights the role of Geographically Weighted Regression (GWR) with an empirical application to a poorly studied issue (i.e., desertification risk), and (ii) evidences the importance of the appropriate spatial scale for analysis of environment-income relationships, suggesting a move beyond traditional variables and territorial domains (mainly of administrative nature). As in the empirical exercise illustrated in Chapter 4, the use of homogeneous districts with economic relevance (and widely used for territorial-environmental analysis) may stimulate a more intense debate on the appropriate unit for analysis of integrated socio-environmental phenomena.

\section{Getting Inside the Environmental Kuznets Curve: Empirics and Criticism}

The EKC hypothesis was formulated to disentangle the global environment-economy nexus from a developmental point of view (Dasgupta et al. 2002; Cole 2007; Galeotti 2007). Some contributions have included the EKC assumption in more formalized theoretical models, stemming from empirical findings (Andreoni and Levinson 2001; Hill and Magnani 2002; Bruvoll et al. 2003). The stylized facts emerging from theoretical and empirical analysis identified an 'inverted-U' relationship between ecosystem degradation and the level of the country's income (Dinda 2004; Jha and Murthy 2003). Consumers characterized by lower incomes, prefer unsustainable commodities resulting in the lack of 'greening' of industrial products and institutional policies (Maddison 2007). Assuming an accelerated wealth creation as a precondition for technological progress, the country's income indirectly sustains a more effective response to environmental degradation (Magnani 2000, 2001; Bimonte 2002). The EKC assumption illustrates a dynamic environment-economy relationship focusing on long-term processes of change (Bimonte and Stabile 2017b). These processes are mainly based on differentiated development paths, which are typical of countries that have experienced sequential stages of growth over time. Earlier studies identified different channels through which economic growth could influence ecosystem functioning and ecological conditions at large, reflecting the structural change, transformations in production scale, and technological progress (Salvati and Carlucci 2010; Chelli and Rosti 2002; Rosti and Chelli 2009; Rosti et al. 2005). Assuming a positive (while indirect) relationship between the economic capital, local communities, and environmental endowments, structural changes used to depend on coexisting dynamics of technology (Ciommi et al. 2018; Lamonica and Chelli 2018; Lamonica et al. 2020). These are both supply-oriented and demand-oriented innovations resembling the effects of the three transmission channels defined above (Jaffe et al. 2005; Rosti and Chelli 2012; Gigliarano and Chelli 2016). EKC studies have focused on specific environmental degradation processes such as short- and long-term air pollution (Ansuategi 2003; Bruvoll and Medin 2003; Aldy 2016), deforestation 
(Barbier et al. 1991; Choumert et al. 2013) and clearcutting (Lantz 2002). Relatively little research dealt with water pollution (Paudel et al. 2005), hazardous wastes (Berrens et al. 1997; Wang et al. 1998), or agricultural land abandonment (James 1999). An even more restricted number of studies addressed the relationship between aggregate indexes of environmental quality (or degradation), sustainable development and income levels (Zaim and Taskin 2000). Recent papers have also investigated the intrinsic relationship between income levels and (i) soil/landscape degradation, (ii) desertification risk, and (iii) urbanization-driven land consumption (Salvati et al. 2011; Bimonte and Stabile 2017a, 2019).

The environment-economy relationship was supposed to be linear (de-coupling hypothesis) or polynomial (re-linking hypothesis). In the former case, economic growth has beneficial effects on environmental quality over the whole range of incomes (Rasli et al. 2018). In the latter case, if economic growth shows beneficial effects on environmental quality at lower (or intermediate) income levels, a 're-linking' process is expected at higher income levels (Chelleri et al. 2015). A country's income used to be associated with improving environmental conditions at the lower and intermediate levels and more stable conditions at the higher ones (Galeotti et al. 2006). The third (or higher-order) polynomial relationships highlight a more complex socio-ecological response as income rises. EKC studies estimate a vector of coefficients, identifying the specific impact of individual drivers on a given environmental process over a sufficiently broad range of income levels (De Bruyn 1997). Reduced form equations incorporating a (more or less) articulated ensemble of additional (non-income) predictors have been used frequently. However, only a partial consensus has been reached on the final specification of generalized income-environment relationships (Ozturk et al. 2016). The most diffused approach was based on the intrinsic comparison of first, second and third (or even higher-order) polynomials, evaluating different specifications for statistical robustness and empirical coherence (Mukherjee and Kathuria 2006). However, linear or polynomial functions can be hardly regarded as fully realistic representations of the economy-environment nexus (Figure 1), which is traditionally complex and intrinsically multi-dimensional and multi-scalar (Maddison 2006). Some specifications were regarded as approximate and simplified representations of a more articulated reality, raising estimation problems and underlining peculiar socio-economic and ecological dimensions. While first-order equations collapse EKC to a basic 'de-coupling' assumption, quadratic specifications imply that environmental degradation will move towards a plus (or minus) infinity as income increases (Mazzanti et al. 2008). Then, the third (or higher level) polynomials lead to N-shaped rather than U-shaped relationships, opening new issues in the economy-environment relationship for policy-making purposes (Sobhee 2004). A vast set of different specifications have been estimated for both income alone and income with additional predictors and covariates, using multivariate analysis and (more or less) refined econometrics (Harbaugh et al. 2000) incorporating: (i) a linear income descriptor (representing a 'de-coupling' baseline); (ii) linear and squared income terms (representing the EKC most usual case); and, (iii) linear, squared, cubic (and, sometimes, even more complex) income terms (representing extensions of the U-shaped curve toward more articulated, N-shaped, relationships).
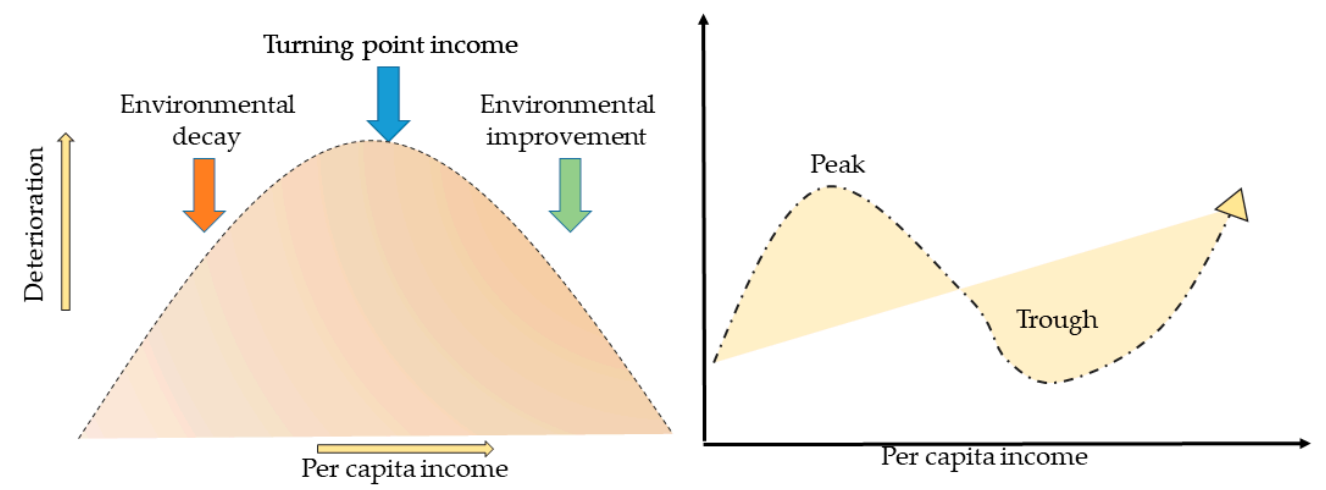

Figure 1. A classical inverted U-shaped Environmental Kuznets Curve (left) and a more complex $\mathrm{N}$-shaped curve (right). 
Additional predictors have been introduced and tested, mainly as linear (or polynomial) terms. While the final choice depends on data availability and research goals, there is no consensus on the type and number of predictors regarded as potential drivers of environmental degradation (Dinda 2004; Stern 1998). Due to this fact, seminal studies have used income as the unique predictor, interpreting the model's goodness-of-fit as a true indicator showing the net impact of economic growth on ecosystems (Galeotti 2007; Li et al. 2016). Heterogeneous drivers of environmental degradation generally include policy factors, socio-economic conditions and place-specific variables depending on the investigated spatial scale (Müller-Fürstenberger and Wagner 2007). However, some authors concluded that heterogeneity of place-specific predictors can prevent a full comparison of local-scale responses related to socio-environmental systems and income growth (Salvati 2014; Zaman et al. 2016; Zoundi 2017). At the same time, some authors have also criticized the EKC assumption (Heerink et al. 2001; Panayotou 1997; Chimeli 2007). We can summarize these concerns as follows: (i) if policy inaction is occurring, a persistent economic growth is not a sufficient condition to reduce human pressure on ecosystems (Ranjan and Shortle 2007); (ii) there is empirical evidence related to the validity of the EKC as a heterogeneous process depending on the environmental process tested (Arrow et al. 1995); and, (iii) this assumption reflects the shift from land-intensive to capital-intensive economic systems characterized by a growing capital availability and decreasing energy profits in the primary sector (Esposito et al. 2018), which could provide partial (and sometimes misleading) information on the total environmental impact. Other minor considerations are based on the assumption that there is no reason to hope that-with increasing wealth - any automatic decline in human pressure and, thus, environmental degradation would occur (Salvati et al. 2012). Only a mix of increasing wealth at both the macro- and micro-levels, a more generalized preference for 'greening' production, community awareness to environmental problems, and policy effectiveness may promote a higher level of ecosystem conservation (Salvati 2014; Heidkamp 2008; Rehman et al. 2012). Despite these above-mentioned criticisms, recent studies still consider EKC as a valid hypothesis to investigate the vast spectrum of the environment-economy relationships all over the world, feeding a normative debate (e.g., Kairis et al. 2015). By underlining the (potentially positive) role of the government policies-usually more ambitious in advanced countries (Barrett and Graddy 2000; Magnani 2000; de Bruyn et al. 1998)—these studies assume that the EKC directly reflects an 'induced policy response' able to outline how societies would demand more stringent environmental standards as income rises (Munasinghe 1999).

\section{Broadening the Debate? Spatial Variability in the Relationship between Environment and Income}

Especially in earlier studies investigating EKC at the global scale, similar economic rules have been frequently applied irrespective of the 'spatial' dimension (Zuindeau 2007). This assumption leads to a generalized application of standardized frameworks to explore spatial agglomeration, territorial specialization, and impacts of regionally differentiated productions on environmental quality at vastly different operational scales (Briassoulis 2005). Although a wealth of empirical studies have dealt with environmental economics in the most recent decades (e.g., Aldy 2016; Nijkamp 1999; Tan 2006), relatively few works integrated the specific knowledge from economic geography and regional science perspectives, addressing spatial issues in the environment-economy nexus (Agras and Chapman 1999; Alam et al. 2016). Coupled with a latent 'lack of interest' in spatially explicit approaches to EKC, the philosophical divergence between traditional (a-spatial) and more innovative (spatial) approaches resulted in a less effective understanding of spatial variability as a powerful driver of the environment-economy nexus (Bradford et al. 2000; Carson 2010; Bilgili et al. 2016).

Using simplified approaches, the causal linkage between regional economic performances and ecological degradation processes has been occasionally investigated, identifying the intrinsic drivers of change that interact at the same spatial scale only in a few cases (Salvati and Zitti 2009a). Although basic contributions to EKC have been grounded on cross-country data analysis for a long time, Ciriaci and Palma (Ciriaci and Palma 2008), likely for the first time, outlined how the EKC is fundamentally 
a within-country story. Differentiating between-countries and within-countries dynamics, Vincent (Vincent 1997) argued how the EKC mostly reflects "the juxtaposition of a positive relationship between pollution and income in developing countries/regions with a fundamentally different, negative one in developed countries, not a single relationship that applies to both categories of countries". Based on these premises, empirical studies have increasingly faced the challenging issue of spatial variability in the income-environment linkage at the regional scale (Smiraglia et al. 2016). Some of these studies have also criticized the quantitative analysis adopted in the earlier literature and have introduced (more or less) sophisticated techniques to estimate equation parameters, questioning the meaning and significance of the observed interactions (Kazemzadeh-Zow et al. 2017). Recent works have investigated the environment-economy nexus and the main determinants at disaggregated (e.g., sub-regional, district, local) spatial units considering representative cases, in connection with a more explicit analysis of the individual response and their environmental impact (Bajocco et al. 2012). Research devoted to the analysis of the income-environment relationship was mainly focused on (i) the role of place-specific factors of change; (ii) the interactions among them; and (iii) the importance of spatial effects.

Compared to the result of cross-country analysis, models incorporating multi-scale elementary data with large spatial coverage from homogeneous small areas to entire ecological regions provide a reliable set of statistical units possible delineating multiple economic-environment behaviors (Deacon and Norman 2006; Awaworyi Churchill et al. 2018). Although limited data variability is an intrinsic feature of such applications, the relevancy for policy-making purposes is generally high. Integrating cross-country and regional-differentiated analysis with district-based qualitative approaches and local inquiries provide the necessary base to a refined knowledge of robust, spatially explicit EKCs, irrespective of the environmental degradation process under investigation (Geoff and Juntti 2005). Assuming different environmental impacts of social change mediated by (more or less) adaptive local contexts, the role of space in the environment-economy relationship is intrinsically linked with socio-economic gradients that account for territorial disparities in the distribution of natural resources (Kim et al. 2018; Madden et al. 2019). More specifically, spatial disparities may reflect (i) economic specialization, (ii) the importance of specific production scales, and (iii) the role of decentralized multi-domain policies containing social inequalities and environmental degradation at vastly different intervention scales (Yamamoto 2008; Kaika and Zervas 2013b; Esposito et al. 2016).

Empirical evidence suggests that environmental externalities play differentiated roles at the country, regional and local scales. Consequently, the sub-regional scale is assumed as a particularly appropriate spatial level to delineate the different forms of the human-environment system, in their past development and in their capacity to suggest new directions of policy (Kairis et al. 2013). The structure of production systems and the interaction between environmental drivers and local communities suggest a more comprehensive analysis of the integrated policy response, distinguishing actions carried out by central governments, regional institutions, and local authorities (Brenner 2003). In this regard, verifying a spatially explicit environment-economy relationship at the different operational scales contributes to a refined understanding of the specific impact of any policy strategy within a range of different 'macro' (cross-country or cross-region) and 'micro' (individual actor, local community, cross-district) dimensions (Destek and Sarkodie 2019; Destek et al. 2018; Expósito et al. 2019). This rationale allows an in-depth investigation of the cumulative (or even adverse-to-income) effects of additional factors observed at the decentralized governance levels (Li et al. 2016; Lin et al. 2016; Gill et al. 2017; Luzzati et al. 2018).

\section{Understanding the Spatially Differentiated Environment-Economy Nexus: The Case of Desertification Risk in Italy}

\subsection{Theoretical Framework}

A better understanding of the spatial variability related to the economy-environment relationship contributes to the design of more effective decentralized policies for natural resource conservation and adapting to specific territorial contexts (Rasli et al. 2018). The empirical analysis of local relationships 
between income and environment should clarify the impact of different institutional, operational, temporal and spatial scales, progressively moving from centralized levels (e.g., countries, administrative regions) to decentralized interactions involving local communities (e.g., prefectures, local labor systems, agricultural and industrial districts, rural areas, homogeneous municipalities and communes). The scale range adopted in spatially explicit EKC exercises should, therefore, consider economic- and policy-relevant analysis' units suitable to classify territorial units into homogeneous aggregates, considering the latent interaction between e.g., landscape and local communities (North 2005).

Intended as policy-relevant spatial units, use of administrative districts, municipalities, or local communities allows a comprehensive investigation of the role of 'decentralized' socio-economic contexts (Recanatesi et al. 2016). In this regard, peculiar territorial characteristics and specific interactions with the environment can be completely ignored when adopting classical, 'centralized' EKC (or similar) approaches (Marston et al. 2005). Homogeneous labor districts, municipalities and local communes represent a suitable spatial domain to match socio-economic information (e.g., income, value-added, production and productivity by economic sector, labor market indicators) with relevant environmental indicators estimated from official statistics (Dumanski et al. 1998). Addressing issues of spatial comparability when combining ecological variables and socio-economic indicators is increasingly required (Delfanti et al. 2016). They are usually calculated, expressed and mapped at vastly different spatial scales and using distinctive geographical domains of aggregation (Incerti et al. 2007). These usually include eco-regions or other spatial partitions with a clear ecosystem meaning and rationale for ecological variables as well as administrative units/boundaries for socio-economic factors. In this context, computational issues such as the Modifiable Area Unit Problem, typical of the ecological analysis of socio-economic dynamics based on indicators aggregated on defined (administrative) spatial scales, can be mitigated. Furthermore, geospatial techniques regionalizing variables over homogeneous lattices would seem appropriate to contain the analysis' bias resulting from such an issue (Bajocco et al. 2011).

Based on these premises, spatially explicit methodologies can be adopted to identify local-based income-environment relationships using more complex analysis' strategies (Salvati and Zitti 2008). Spatial econometrics could provide a wealth of statistical techniques suitable to investigate this issue (Xie et al. 2019). However, relatively few techniques may identify the specificity of local-scale relationships starting from global income-environment relationships (Balado-Naves et al. 2018). The Geographically Weighted Regression (GWR) (Fotheringham et al. 2002) is a possible solution controlling for spatial structures that characterize the dependent variable (environment) and predictor(s) (income and, eventually, additional variables). It allows the estimation of a local regression model for each spatial unit in a given area. Being extensively used in a broad number of applications and disciplinary fields, the GWR approach is an appropriate methodology accounting for spatial dependence and heterogeneity (Rontos et al. 2016). Adopting various functions (including Kernel and other flexible spline approaches) to calculate weights for the estimation of local regression models, the methodological framework underlying GWR is similar to that of a traditional regression model. However, contrary to a spatially implicit ordinary least square regression (with location invariant regression coefficients), the specification of a basic GWR model for each location $s=1, \ldots, n$, is:

$$
Y(s)=X(s) B(s)+e(s)
$$

where $\mathrm{Y}(\mathrm{s})$ is the dependent variable at location $\mathrm{s}, \mathrm{X}(\mathrm{s})$ represents the predictor at location $\mathrm{s}, \mathrm{B}(\mathrm{s})$ means the column vector of regression coefficients at location $\mathrm{s}$, and $\mathrm{e}(\mathrm{s})$ acts as the random error at location s. Hence, regression parameters estimated at each location by weighted least squares are spatially explicit. This implies that each coefficient in the model is a function of $s$, a point within the investigated geographical space. As a result, GWR gives rise to a distribution of local estimated parameters. The weighting scheme is expressed as a function (e.g., bi-square nearest neighbor kernel function, one of the most commonly used specifications) that places more weight on the observations closer to the location $s$ (Salvati and Serra 2016). Coefficients of determination $\left(\mathrm{R}^{2}\right)$ and error values are estimated at the local 
scale, providing indirect indications about stability over time, internal coherence and reliability of the GWR model (Ali et al. 2016). Limitations regarding the use of GWR only arise with the interpretation of extreme regression coefficients, or when drawing conclusions based on a reduced number of sample observations (Kaika and Zervas 2013a).

\subsection{Empirical Approach}

Desertification risk is considered a particularly important issue in the political agenda for the 21st century as the leading process of land resource depletion (Recanatesi et al. 2016). Defined as a long-term decline in ecosystem functions and productivity, the land exposed to degradation increased worldwide, being particularly severe in Africa, Southern Asia, and Latin America, and becoming progressively more intense in wealthier economies in North America, Australia, and Europe (Delfanti et al. 2016). Thanks to climate change and growing human pressure, more than half of Mediterranean European land is sensitive to desertification (Kairis et al. 2015). Desertification risk is regarded as a composite process depending on biophysical, cultural, and institutional drivers acting together, with negative effects on food security and quality of life (Kairis et al. 2013). The incompleteness of scientific knowledge on the local relationship between desertification risk and economic performances may depend on the fact that social sciences have sometimes underestimated the significance of such issues, missing the importance of multi-scale assessment frameworks (Bajocco et al. 2011, 2012; Salvati et al. 2016).

As a paradigmatic example of the importance of local contexts in the analysis of environment-income dynamics, the relationship between a composite index of desertification risk and per-capita value-added produced at the local scale was modelled using a Geographically Weighted Regression in 686 economically homogeneous districts before the 2007 economic crisis in Italy. This country represents an advanced economy in Mediterranean Europe with significant socio-economic disparities and vast areas currently (or potentially) affected by desertification risk (Geoff and Juntti 2005). Therefore, desertification risk was assessed here based on the Environmentally Sensitive Area Index (the so-called ESAI), a comprehensive methodology used widely for evaluation of local-scale processes of land degradation (Kim et al. 2018; Madden et al. 2019; Yamamoto 2008). This methodology is composed of 14 basic variables assessing climate, soil, vegetation and land-use quality as proxies of land degradation processes (see below) as concluded by other studies (Bajocco et al. 2012; Karamesouti et al. 2015; Kosmas et al. 2016).

In the present study, per-capita value added was assumed as a reliable indicator of local competitiveness and economic performances of a given spatial unit, such as a local district (Ferrara et al. 2016). For the first time in Italy, and likely in Europe, official statistics of per-capita value added were provisionally released by the Italian National Statistical Institute (ISTAT) at the district level (local labor systems), providing a unique opportunity to test for the local impact of average income levels on a relevant process of environmental degradation. Release of official statistics of value-added and incomes at the district level was considered experimental and covered only a few years at the beginning of the 2000s (Salvati and Carlucci 2010). We used a Geographically Weighted Regression to provide local regression estimates of the impact of per-capita value-added on the level of desertification risk in Italy, giving an adjusted $R^{2}$ value for the global model as well as a set of local $R^{2}$, slope coefficients, intercepts and standardized residuals for each local labor system at the most recent study year (2005) with a complete estimation of per-capita income at the same spatial level. These conditions can be assumed as representative of economic expansion with moderate/low rates of growth, common to several Mediterranean countries (Salvati 2016).

\subsection{Estimating Desertification Risk in Italy}

The ESAI framework defines different levels of desertification risk as a combination of possibly unsustainable land management together with a particular set of environmental factors including poor soil/vegetation and dry climate (Salvati et al. 2016). The elementary variables used to locally estimate the level of desertification risk in Italy refer to the ESAI framework being grouped in four 
dimensions of environmental quality: climate, soil, vegetation/land use, and human pressure/land management (Delfanti et al. 2016). The most accurate, detailed and updated layers currently available in Italy were used at a basic resolution of 1:25,000, which is suitable for a local-level assessment of desertification risk (Recanatesi et al. 2016). The reference year of all elaborations is 2005. Following the ESAI model, the following variables were adopted to estimate climate quality: average annual rainfall rate, aridity index, and aspect (Salvati et al. 2012). Mean annual rainfall and aridity were derived from a national climate database regionalizing elementary data derived from nearly 3000 meteorological stations distributed all over Italy and functioning since 1951 (Scarascia et al. 2006). Aridity index was calculated according to UNEP (United Nations Environment Programme) formulation, considering the ratio of total precipitation and reference evapotranspiration every year. The aspect was obtained from a $20 \mathrm{~m}$ Digital Terrain Model of Italy provided by the Italian Minister of Environmental Protection (Rome).

Soil data were derived from: (i) the European Soil Database (Joint Research Center, JRC) at a $1 \mathrm{~km}^{2}$ pixel resolution, integrated with national information sources (an Italian database of soil characteristics ('Map of the water capacity in agricultural soils') generated by the Ministry of Agriculture and based on nearly 18,000 soil samples; (ii) thematic sources including Eco-pedological and Geological maps of Italy, obtained from the Joint Research Centre and the Italian Geological Service, and a map of land systems produced by the National Centre of Soil Cartography (Florence). These datasets were assumed as the most homogeneous and spatially detailed soil information for Italy, being available at 1:250,000 scale (Bajocco et al. 2011). According to the standard ESAI model, we considered the following variables: soil depth and texture, slope, and the nature of the parent material. These variables were assumed as proxies of other soil quality indicators, e.g., organic matter content, resistance or tendency to compact (Kairis et al. 2013). The specific contribution of land cover/land-use on desertification risk was assessed through four variables: vegetation cover, fire risk, the protection offered by vegetation against soil erosion, and the degree of resistance to drought provided by vegetation (Bajocco et al. 2012). Such indicators were obtained from the elaboration of a CORINE (Coordination of Information on the Environment) land cover map (2006) provided by the European Environment Agency (EEA). The four variables described below were calculated using a weighting system (ranging from one to two and derived from (Salvati et al. 2016)) that classifies the observed land cover class according to the level of desertification risk.

Anthropogenic pressure and land management quality were finally evaluated as the result of population dynamics and landscape transformations (e.g., urbanization, agricultural intensification). Population density and annual growth rate were used as summary indicators of human pressure (Salvati et al. 2012). The population density was measured at municipal scale in 2005 based on the annual Population Register held by the Italian National Institute of Statistics (ISTAT). Population increase (or decrease) was determined as the annual population change (\%) observed at the municipal scale between 2002 and 2005. An indicator of land intensity was finally calculated applying a weighting system (ranging from one to two) that classifies the observed CORINE class according to the intensity of use and potential level of desertification risk (Recanatesi et al. 2016). Based on the estimated degree of correlation between each characteristic dimension and desertification risk, the scoring system suggested by Salvati et al. (Salvati et al. 2016) —ranging between one (the lowest contribution to desertification risk) and two (the highest contribution to desertification risk) — was applied to each variable in the ESAI. Quality indicators (climate: CQI, soil: SQI, vegetation/land-use: VQI, human pressure/land management: MQI) were estimated as the geometric mean of the different scores assigned to each input variable. Ranging between one (the lowest desertification risk) and two (the highest desertification risk), the ESAI was then estimated at each spatial unit as the geometric mean of the four quality indicators as follows (Salvati and Zitti 2005):

$$
\mathrm{ESAI}=\left(\mathrm{SQI}{ }^{*} \mathrm{CQI}{ }^{*} \mathrm{VQI}{ }^{*} \mathrm{MQI}\right)^{1 / 4}
$$




\subsection{Applying the Geographically Weighted Regression to Assess Desertification Risk in Italy}

Results of the statistical analysis are illustrated in Figure 2. Goodness-of-fit of the global model was particularly high (adjusted $\mathrm{R}^{2}=0.70$ ), although local $\mathrm{R}^{2}$ coefficients, slope coefficients and intercepts varied largely over space. The highest $\mathrm{R}^{2}$ coefficients were observed in a large part of Northern Italy coinciding with the Po plain, an area characterized by high human pressure and classified as potentially affected by desertification risk. The specific impact of per-capita value added was highly positive in the Po Plain and along the Adriatic Sea coast in central Italy, as the $\mathrm{R}^{2}$ coefficient clearly illustrated (Figure 2, upper left). These districts were characterized by a locally high anthropogenic pressure (reflected in e.g., population concentration, landscape simplification, and crop intensification). Increasing incomes in such contexts correspond to a higher level of desertification risk, as slope coefficients systematically higher than one indicate (Figure 2, upper right). However, wealthier districts in the Alpine and Pre-Alpine regions registered a negative income-environment linkage (negative slope coefficients), being often reflected in a lower level of desertification risk.

Conversely, the specific impact of economic growth was often negative in both internal and coastal districts of southern Italy, a region classified at risk of desertification in the National Action Plan to Combat Desertification. Negative slope coefficients were especially observed in the Abruzzo, Campania, Molise and Apulia regions, and more sparsely in Calabria, Sicily and Sardinia. In these areas-mostly rural districts with traditional agriculture and low population density-increasing incomes do not have a negative impact on desertification risk, because of moderate human pressure. Residuals' estimates complete the model's results, indicating spatial randomness of statistical errors. The empirical association between district slope coefficient (y) derived from GWR (Figure 2, upper right map) and per-capita value added ( $\mathrm{x}$ ) was best fitted using a second-order polynomial equation (y $=-1 \mathrm{e}^{-9} \mathrm{x}^{2}+8 \mathrm{e}^{-5} \mathrm{x}-0.546, \mathrm{R}^{2}=0.30, \mathrm{n}=686$ districts). The threshold for the positive (or negative) impact of income on desertification risk was estimated at around 30,000 euros per head. Income levels had a positive impact on desertification risk in districts producing a value-added above this threshold. In economic districts with a per-capita value-added below this threshold, increasing income levels were associated, on average, with increasing levels of desertification risk.
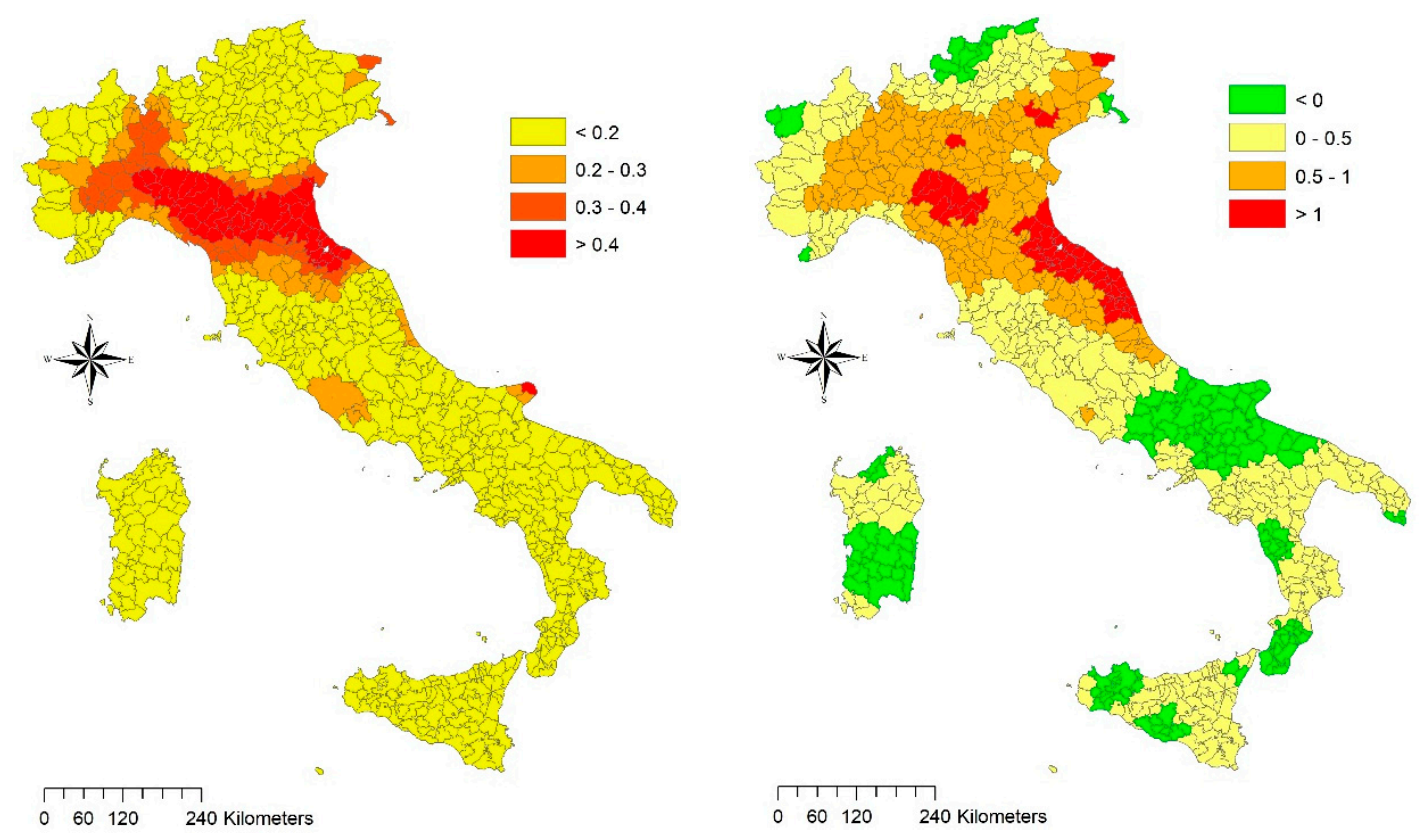

Local R2

Slope coefficient

Figure 2. Cont. 


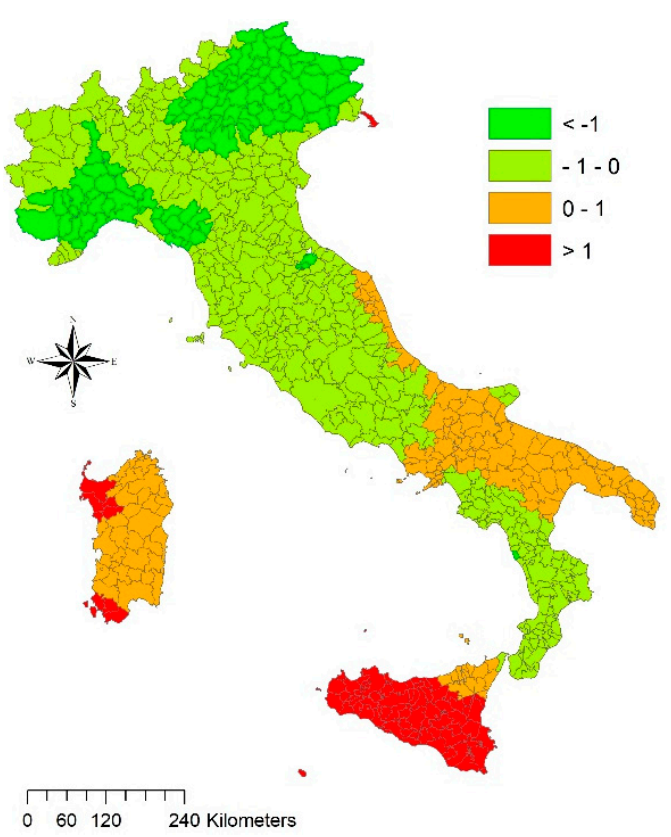

Intercept

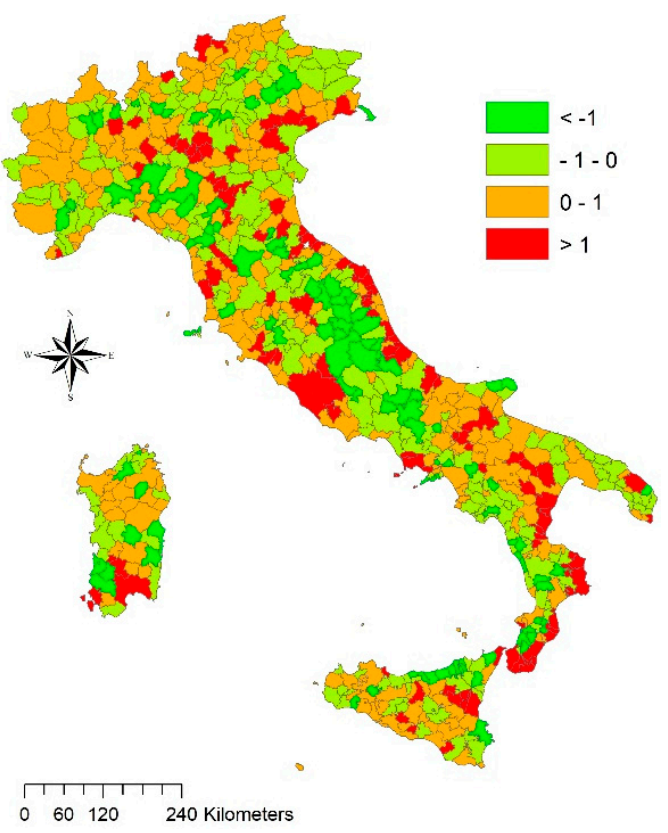

Standardized residuals

Figure 2. Results of a Geographically Weighted Regression for the level of desertification risk (dependent variable) and per-capita value added (predictor) at the local district scale in Italy (2005).

\section{Discussion}

This commentary provides a literature review of past and recent studies on the Environmental Kuznets Curve and a local analysis of the relationship between a specific environmental process and economic development at the district scale in Italy. Based on a local regression approach, the results of this quantitative exercise can be considered when developing more effective policies aimed at mitigating environmental degradation in Mediterranean-type ecosystems (Salvati et al. 2012). The empirical findings of the analysis suggest that a significant correlation exists between desertification risk and the level of economic growth in the Italian local districts (Salvati and Carlucci 2010), being differentiated largely over space. More specifically, results of the GWR suggest that the relationship between income and desertification risk follows a U-shaped form compatible with the Environmental Kuznets Curve (Salvati and Zitti 2008). As expected from the relatively low human pressure, desertification risk was moderate in economically disadvantaged local districts (Recanatesi et al. 2016). However, growing incomes-likely determining a rising human pressure-were associated with higher levels of desertification risk, promoting e.g., negative externalities of economic activity. Conversely, in the wealthiest local districts, growing incomes were associated with lower levels of desertification risk, stimulating positive externalities of e.g., environmental protection. This general trend can be further decomposed at the local scale, evidencing spatial peculiarities going beyond the traditional administrative boundaries (e.g., regions, prefectures) adopted in earlier studies (Delfanti et al. 2016), as well as in official environmental reporting and statutory policy acts (e.g., the National Action Plan to combat desertification). These sources give general policy indications for Italy and provide some specific suggestions for a regional strategy against desertification, while demising local interventions that may greatly benefit from the results of this study (Salvati et al. 2012).

Considering local outcomes of a Geographically Weighted Regression model (and, more specifically, local $R^{2}$ and slope coefficients), this example illustrates the advantages of a local-scale investigation of the environment-income relationship for policy impact analysis, evidencing the fine-grain geography of positive (or negative) externalities of increasing income levels. Giving room to a refined analysis of place-specific Kuznets curves, these findings reveal the importance of decentralized strategies of risk containment, accounting for partially differentiated—and mostly non-linear-impacts of local income 
on desertification risk (Delfanti et al. 2016; Cecchini et al. 2019). At the same time, although potentially useful when making exploratory analysis, the EKC mechanism needs refinement when interpreting the inherent complexity of the human-environment interactions. Local-scale analyses contribute to such a deserving issue (Bajocco et al. 2012). While income is a significant variable determining the development stage of a region-having feedback effects on the environment through indirect mechanisms by e.g., increasing the demand for higher environmental quality-the process itself is assumed to be more complex as several other variables can take part in the same relationship (Salvati and Zitti 2005). However, assuming per-capita value-added as a proxy of the economic performances of a local district, with local regressions based on the income level as the unique predictor provides an honest estimation of the spatially varying extent and direction of the income-environment relationship (considering together the local $\mathrm{R}^{2}$ and slope coefficients). Districts with high $\mathrm{R}^{2}$ and a highly positive (or negative) slope coefficient are those where the income-environment relationship was more intense. Districts with moderate $\mathrm{R}^{2}$ and a low slope coefficient delineate a less intense income-environment linkage, possibly shaped by territorial characteristics and peculiar social contexts. In both cases, these results inform policies that may specifically impact processes of change at a local scale, avoiding generalized approaches to mitigate land degradation. At the same time, the results of a local-scale analysis may confirm how integrated policy measures at different spatial scales represent a coherent response against the multiple factors contributing to desertification risk (Kairis et al. 2015)

The empirical exercise proposed in this commentary outlines the importance of fine-grained territorial data of the environment-economy relationship analyzed through spatially explicit local techniques (Scarascia et al. 2006). Lack of geo-referenced point data (or high-resolution, polygon or grid aggregate information), especially for key socio-economic variables, limits the applicability of spatially explicit analysis of local income-environment relationships. Even in advanced countries, relatively little (comparable) information on the environment-economy relationship is available at the different spatial levels (regions, districts, municipalities, ecological/agricultural units, and homogeneous domains of environmental interest/relevance). The reasons at the base of such a data shortage include (i) the difficult assessment of some environmental processes at the disaggregated spatial scales; (ii) the different importance of biophysical, social, economic, institutional, political, and cultural drivers, and (iii) non-linear and multivariate interactions among these drivers (Salvati and Carlucci 2010). An even more complex issue is the selection of an adequate temporal scale of investigation when deriving a theoretical framework for the environment-economy relationship (Incerti et al. 2007). This issue depends on the fact that environmental degradation processes do not follow linear dynamics, being instead linked to point or widespread sources of emissions and depending on different biophysical processes and/or interactions (Rodrigo-Comino et al. 2018; Cerdà et al. 2010).

The systematic collection of information, especially when it is based on field surveys and statistical sampling, is often carried out for merely administrative purposes (Salvati 2016). At the same time, official environmental reporting is based primarily on regionalized information collected at aggregate spatial units of administrative nature and relevance. These domains are unsuitable for analysis and interpretation of phenomena that do not directly follow the political boundaries of a state, a region or a prefecture. Remote sensing can overcome some constraints in the analysis of environmental processes, providing spatial information on regular geometry lattices, i.e., grids (Bajocco et al. 2012). However, only some specific processes of environmental degradation can be permanently monitored considering the outcome of satellite imagery elaboration alone (Bajocco et al. 2011). More frequently, remote sensing results require integration with ancillary (direct) field surveys, official statistics, and digital mapping to provide an appropriate evaluation of complex environmental degradation processes. Environmental statistics have, in turn, a less solid and prolonged tradition over time than those related to social and economic issues, improved for a long time through censuses, sample surveys and the use of strictly administrative sources (e.g., population and business registers).

Environmental surveys considering small sample sizes sometimes have estimation errors that do not allow a particularly reliable spatial analysis. The growing use of spatially explicit methodologies 
and integrated management of geo-referenced databases (e.g., Geographic Information Systems), better integration with satellite imagery, and the increasing diffusion of geostatistical techniques, are elements that envisage a greater availability of quantitative information and reliable environmental measures (Salvati and Zitti 2009c). At the same time, further research efforts should be devoted to identifying ecologically relevant spatial units, proposing a new view of the environment-economy from a non-economic perspective (Salvati and Zitti 2009b). As many studies highlight, regional and local administrative units are often under-representative of complex environmental dynamics at the base of degradation processes, affecting the estimation of EKC (Esposito et al. 2018). These units should be designed to allow a comparative analysis of meaningful environmental indicators and integration with reliable socio-economic variables. Being grounded on criteria of ecological homogeneity, these domains are optimal to depict the impact of environmental policies at both regional and local levels of governance (Özokcu and Özdemir 2017). Based on these premises, the spatial variability of the environment-economy relationship characteristic of a given territorial context and the ecological process, can be interpreted as a key dimension in monitoring programs and policy strategies (Katircioğlu and Katircioğlu 2018). The intrinsic influence on the environment-economy relationships indicates costs and benefits when adopting different but spatially coordinated disaggregated analysis' levels.

\section{Conclusions}

Since the EKC is a rather simplistic assumption of the complex environment-economy relationships, the underlying mechanisms were mostly seen as statistically automatic and not causative. As clearly highlighted in the exercise proposed in this commentary, the value-added of the EKC hypothesis was to provide further insights into the decentralized environment-economy dynamics. While cross-country analysis may represent a fruitful research issue in ecological economics, moving to disaggregated analysis' scales and spatially explicit approaches is a strategy containing technical problems associated with the comparison of aggregated data from different countries. Reflecting endogenous dynamics of de-coupling (or re-linking) wealth and environmental quality, the increasing gap between lowand high-income areas suggests that the role of mitigation-oriented policies and their impact on ecosystems is differentiated across regions. As clarified in our empirical exercise, spatially explicit approaches to EKC - particularly useful in the analysis of the intrinsic environment-income relationship of diffused processes of ecological degradation require the use of refined elementary data and variables derived from official statistics, whose collection should move from strictly administrative domains to innovative territorial units based on homogeneous socio-economic criteria and with relevance for environmental assessment.

Italy represents an example of the possible increasing gap, fuelled by the income-driven dynamics emerging between lower and higher-income areas. The different role of mitigation-oriented policies and their impact on desertification risk in the northern and southern regions of the country can be extensively analyzed using our approach (Salvati and Zitti 2009b). In such a context, coordination of multi-scale (national, regional, local) and multi-target (economic, social, environmental) policies is expected to improve the effectiveness of strategies mitigating desertification risk (Briassoulis 2005). In this regard, focusing on locally-based EKCs provides indications to inform place-specific policies under comparable socio-economic contexts and biophysical conditions. Intimate knowledge of the local relations between the economy and the environment makes it possible to translate centralized and generalized intervention strategies into the specificity of each regional context, mitigating degradation processes more effectively. A decentralized and locally based response to environmental degradation stimulates a more rapid adaptation to external shocks, enhancing the resilience capacity of local economic systems. While consensus on optimal indicators and methodologies for local EKCs does not exist, different measures and approaches have different implications and interpretations. For instance, composite indexes should be preferred when assessing more complex environmental phenomena. Cross-scale integration of policy measures (e.g., environmental measures at the individual level, social measures at the municipal level, economic policies at regional or national levels) may represent a 
coherent response to spatially differentiated drivers of change. In such a context, spatially coordinated multi-scale policies are expected to improve the effectiveness of mitigation and adaptation strategies to any process of environmental degradation in the light of sustainable development.

Author Contributions: Conceptualization, L.S. and A.C.; methodology, E.M.M. and J.R.-C.; investigation, F.G. and J.R.-C.; resources, E.M.M.; writing - original draft preparation, E.C. and L.S.; writing-review and editing, F.G., J.R.-C. and E.M.M.; visualization, A.C. and J.R-C.; supervision, A.C. and J.R-C.; project administration, E.C.; funding acquisition, F.G. All authors have read and agreed to the published version of the manuscript.

Funding: This research received no external funding.

Conflicts of Interest: The authors declare no conflict of interest.

\section{References}

Agras, Jean, and Duane Chapman. 1999. A Dynamic Approach to the Environmental Kuznets Curve Hypothesis. Ecological Economics 28: 267-77. [CrossRef]

Akhtar-Schuster, Mariam, Lindsay C. Stringer, Alexander Erlewein, Graciela Metternicht, Sara Minelli, Uriel Safriel, and Stefan Sommer. 2017. Unpacking the concept of land degradation neutrality and addressing its operation through the Rio Conventions. Journal of Environmental Management 195: 4-15. [CrossRef] [PubMed]

Alam, Md. Mahmudul, Md. Wahid Murad, Abu Hanifa Md. Noman, and Ilhan Ozturk. 2016. Relationships among Carbon Emissions, Economic Growth, Energy Consumption and Population Growth: Testing Environmental Kuznets Curve Hypothesis for Brazil, China, India and Indonesia. Ecological Indicators 70: 466-79. [CrossRef]

Aldy, J. E. 2016. An Environmental Kuznets Curve Analysis of U.S. State-Level Carbon Dioxide Emissions. The Journal of Environment \& Development 14: 48-72. [CrossRef]

Ali, Kamar, Mark D. Partridge, and M. Rose Olfert. 2016. Can Geographically Weighted Regressions Improve Regional Analysis and Policy Making? International Regional Science Review 30: 300-29. [CrossRef]

Andreoni, James, and Arik Levinson. 2001. The Simple Analytics of the Environmental Kuznets Curve. Journal of Public Economics 18: 269-86. [CrossRef]

Anselin, Luc. 2001a. Spatial Effects in Econometric Practice in Environmental and Resource Economics. American Journal of Agricultural Economics 83: 705-10. [CrossRef]

Anselin, L. 2001b. Rao's score test in spatial econometrics. Journal of Statistical Planning and Inference 97: 113-39. [CrossRef]

Ansuategi, Alberto. 2003. Economic Growth and Transboundary Pollution in Europe: An Empirical Analysis. Environmental and Resource Economics 26: 305-28. [CrossRef]

Arrow, Kenneth, Bert Bolin, Robert Costanza, Partha Dasgupta, Carl Folke, C. S. Holling, Bengt-Owe Jansson, Simon Levin, Karl-Goran Maler, Charles Perrings, and et al. 1995. Economic Growth, Carrying Capacity, and the Environment. Ecological Economics 15: 91-95. [CrossRef]

Auffhammer, Maximilian, and Richard T. Carson. 2008. Forecasting the Path of China's CO2 Emissions Using Province-Level Information. Journal of Environmental Economics and Management 55: 229-47. [CrossRef]

Awaworyi Churchill, Sefa, John Inekwe, Kris Ivanovski, and Russell Smyth. 2018. The Environmental Kuznets Curve in the OECD: 1870-2014. Energy Economics 75: 389-99. [CrossRef]

Bajocco, Sofia, Luca Salvati, and Carlo Ricotta. 2011. Land Degradation versus Fire: A Spiral Process? Progress in Physical Geography: Earth and Environment 35: 3-18. [CrossRef]

Bajocco, Sofia, Antonella De Angelis, and Luca Salvati. 2012. A Satellite-Based Green Index as a Proxy for Vegetation Cover Quality in a Mediterranean Region. Ecological Indicators 23: 578-87. [CrossRef]

Balado-Naves, Roberto, José Francisco Baños-Pino, and Matías Mayor. 2018. Do Countries Influence Neighbouring Pollution? A Spatial Analysis of the EKC for $\mathrm{CO}_{2}$ Emissions. Energy Policy 123: 266-79. [CrossRef]

Barbier, Edward B., Joanne C. Burgess, and Anil Markandya. 1991. The Economics of Tropical Deforestation. Ambio 20: 55-58. [CrossRef]

Barrett, Scott, and Kathryn Graddy. 2000. Freedom, Growth, and the Environment. Environment and Development Economics 5: 433-56. [CrossRef]

Berrens, Robert P, Alok K Bohara, Kishore Gawande, and Pingo Wang. 1997. Testing the Inverted-U Hypothesis for US Hazardous Waste: An Application of the Generalized Gamma Model. Economics Letters 55: 435-40. [CrossRef] 
Bilgili, Faik, Emrah Koçak, and Ümit Bulut. 2016. The Dynamic Impact of Renewable Energy Consumption on $\mathrm{CO}_{2}$ Emissions: A Revisited Environmental Kuznets Curve Approach. Renewable and Sustainable Energy Reviews 54: 838-45. [CrossRef]

Bimonte, Salvatore. 2002. Information Access, Income Distribution, and the Environmental Kuznets Curve. Ecological Economics 41: 145-56. [CrossRef]

Bimonte, Salvatore, and Arsenio Stabile. 2017a. Land Consumption and Income in Italy: A Case of Inverted EKC. Ecological Economics 131: 36-43. [CrossRef]

Bimonte, Salvatore, and e Arsenio Stabile. 2017b. EKC and the Income Elasticity Hypothesis Land for Housing or Land for Future? Ecological Indicators 73: 800-8. [CrossRef]

Bimonte, Salvatore, and Arsenio Stabile. 2019. The Effect of Growth and Corruption on Soil Sealing in Italy: A Regional Environmental Kuznets Curve Analysis. Environmental and Resource Economics 74: 1497-518. [CrossRef]

Boyce, James K. 1994. Inequality as a Cause of Environmental Degradation. Ecological Economics 11: 169-78. [CrossRef]

Bradford, David F, Rebecca Schlieckert, and Stephen H Shore. 2000. The Environmental Kuznets Curve: Exploring A Fresh Specification. Working Paper 8001. Contributions to Economic Analysis E Policy 4: 5. [CrossRef]

Brenner, Neil. 2003. Metropolitan Institutional Reform and the Rescaling of State Space in Contemporary Western Europe. European Urban and Regional Studies 10: 297-324. [CrossRef]

Briassoulis, H. 2005. Policy Integration for Complex Environmental Problems: The Example of Mediterranean Desertification. London: Routledge.

Bruvoll, Annegrete, and Hege Medin. 2003. Factors behind the Environmental Kuznets Curve. A Decomposition of the Changes in Air Pollution. Environmental and Resource Economics 24: 27-48. [CrossRef]

Bruvoll, Annegrete, Taran Fæhn, and Birger Strøm. 2003. Quantifying Central Hypotheses on Environmental Kuznets Curves for a Rich Economy: A Computable General Equilibrium Study. Scottish Journal of Political Economy 50: 149-73. [CrossRef]

De Bruyn, Sander M. 1997. Explaining the Environmental Kuznets Curve: Structural Change and International Agreements in Reducing Sulphur Emissions. Environment and Development Economics 2: 485-503. [CrossRef]

de Bruyn, S. M, J. C. J. M van den Bergh, and J. B Opschoor. 1998. Economic Growth and Emissions: Reconsidering the Empirical Basis of Environmental Kuznets Curves. Ecological Economics 25: 161-75. [CrossRef]

Carson, Richard T. 2010. The Environmental Kuznets Curve: Seeking Empirical Regularity and Theoretical Structure. Review of Environmental Economics and Policy 4: 3-23. [CrossRef]

Caviglia-Harris, Jill L., Dustin Chambers, and James R. Kahn. 2009. Taking the "U” out of Kuznets: A Comprehensive Analysis of the EKC and Environmental Degradation. Ecological Economics 68: 1149-59. [CrossRef]

Cavlovic, Therese A., Kenneth H. Baker, Robert P. Berrens, and Kishore Gawande. 2000. A Meta-Analysis of Environmental Kuznets Curve Studies. Agricultural and Resource Economics Review 29: 1-11. [CrossRef]

Cecchini, Massimo, Ilaria Zambon, Antonella Pontrandolfi, Rosario Turco, Andrea Colantoni, Anastasios Mavrakis, and Luca Salvati. 2019. Urban Sprawl and the 'Olive' Landscape: Sustainable Land Management for 'Crisis' Cities. GeoJournal 84: 237-55. [CrossRef]

Cerdà, A., H. Lavee, A. Romero-Díaz, J. Hooke, and L. Montanarella. 2010. Preface: Soil erosion and degradation in mediterranean type ecosystems. Land Degradation and Development 21: 71-74. [CrossRef]

Chelleri, L., T. Schuetze, and L. Salvati. 2015. Integrating Resilience with Urban Sustainability in Neglected Neighborhoods: Challenges and Opportunities of Transitioning to Decentralized Water Management in Mexico City. Habitat International 48: 122-30. [CrossRef]

Chelli, Francesco, and Luisa Rosti. 2002. Age and gender differences in Italian workers' mobility. International Journal of Manpower 23: 313-25. [CrossRef]

Chimeli, Ariaster B. 2007. Growth and the Environment: Are We Looking at the Right Data? Economics Letters 96: 89-96. [CrossRef]

Choumert, Johanna, Pascale Combes Motel, and Hervé K. Dakpo. 2013. Is the Environmental Kuznets Curve for Deforestation a Threatened Theory? A Meta-Analysis of the Literature. Ecological Economics 90: 19-28. [CrossRef] 
Ciommi, Mariateresa, Francesco M. Chelli, Margherita Carlucci, and Luca Salvati. 2018. Urban Growth and Demographic Dynamics in Southern Europe: Toward a New Statistical Approach to Regional Science. Sustainability 10: 2765. [CrossRef]

Ciriaci, Daria, and Daniela Palma. 2008. The Role of Knowledge-Based Supply Specialisation for Competitiveness: A Spatial Econometric Approach*. Papers in Regional Science 87: 453-75. [CrossRef]

Cole, Matthew A. 2007. Corruption, Income and the Environment: An Empirical Analysis. Ecological Economics 62: 637-47. [CrossRef]

Dasgupta, Susmita, Benoit Laplante, Hua Wang, and David Wheeler. 2002. Confronting the Environmental Kuznets Curve. Journal of Economic Perspectives 16: 147-68. [CrossRef]

Dasgupta, Susmita, Kirk Hamilton, Kiran D. Pandey, and David Wheeler. 2006. Environment during Growth: Accounting for Governance and Vulnerability. World Development 34: 1597-611. [CrossRef]

Deacon, Robert T., and Catherine S. Norman. 2006. Does the Environmental Kuznets Curve Describe How Individual Countries Behave? Land Economics 82: 291-315. [CrossRef]

Delfanti, Lavinia, Andrea Colantoni, Fabio Recanatesi, Massimiliano Bencardino, Adele Sateriano, Ilaria Zambon, and Luca Salvati. 2016. Solar Plants, Environmental Degradation and Local Socioeconomic Contexts: A Case Study in a Mediterranean Country. Environmental Impact Assessment Review 61: 88-93. [CrossRef]

Destek, Mehmet Akif, and Samuel Asumadu Sarkodie. 2019. Investigation of Environmental Kuznets Curve for Ecological Footprint: The Role of Energy and Financial Development. Science of The Total Environment 650: 2483-89. [CrossRef]

Destek, Mehmet Akif, Recep Ulucak, and Eyup Dogan. 2018. Analyzing the Environmental Kuznets Curve for the EU Countries: The Role of Ecological Footprint. Environmental Science and Pollution Research 25: 29387-96. [CrossRef]

Dinda, Soumyananda. 2004. Environmental Kuznets Curve Hypothesis: A Survey. Ecological Economics 49: 431-55. [CrossRef]

Dumanski, J., W. W. Pettapiece, and R. J. McGregor. 1998. Relevance of Scale Dependent Approaches for Integrating Biophysical and Socio-Economic Information and Development of Agroecological Indicators. Nutrient Cycling in Agroecosystems 50: 13-22. [CrossRef]

Esposito, Piero, Fabrzio Patriarca, Luigi Perini, and Luca Salvati. 2016. Land Degradation, Economic Growth and Structural Change: Evidences from Italy. Environment, Development and Sustainability 18: 431-48. [CrossRef]

Esposito, Piero, Fabrizio Patriarca, and Luca Salvati. 2018. Tertiarization and Land Use Change: The Case of Italy. Economic Modelling 71: 80-86. [CrossRef]

Expósito, Alfonso, María Pablo-Romero, and Antonio Sánchez-Braza. 2019. Testing EKC for Urban Water Use: Empirical Evidence at River Basin Scale from the Guadalquivir River, Spain. Journal of Water Resources Planning and Management 145: 04019005. [CrossRef]

Ferrara, Agostino, Claire Kelly, Geoff A. Wilson, Angelo Nolè, Giuseppe Mancino, Sofia Bajocco, and Luca Salvati. 2016. Shaping the Role of $<$ fast $>$ and $<$ Slow $>$ Drivers of Change in Forest-Shrubland Socio-Ecological Systems. Journal of Environmental Management 169: 155-66. [CrossRef]

Fingleton, Bernard. 2016. Externalities, Economic Geography, And Spatial Econometrics: Conceptual and Modeling Developments. International Regional Science Review. [CrossRef]

Fotheringham, A. S., C. Brunsdon, and M. Charlton. 2002. Geographically Weighted Regression: The Analysis of Spatially Varying Relationships. Hoboken: Wiley.

Franceschi, Dina, and James R. Kahn. 2003. Beyond strong sustainability. International Journal of Sustainable Development \& World Ecology 10: 211-20. [CrossRef]

Galeotti, Marzio. 2007. Economic Growth and the Quality of the Environment: Taking Stock. Environment, Development and Sustainability 9: 427-54. [CrossRef]

Galeotti, Marzio, Alessandro Lanza, and Francesco Pauli. 2006. Reassessing the Environmental Kuznets Curve for $\mathrm{CO}_{2}$ Emissions: A Robustness Exercise. Ecological Economics 57: 152-63. [CrossRef]

Geoff, A. Wilson, and Meri Juntti, eds. 2005. Unravelling Desertification. Wageningen: Wageningen Academic Publishers. [CrossRef]

Gigliarano, Chiara, and Francesco Maria Chelli. 2016. Measuring Inter-Temporal Intragenerational Mobility: An Application to the Italian Labour Market. Quality \& Quantity 50: 89-102. [CrossRef]

Gill, Abid Rashid, Kuperan K. Viswanathan, and Sallahuddin Hassan. 2017. Is Environmental Kuznets Curve Still Relevant? International Journal of Energy Economics and Policy 7: 156-65. 
Harbaugh, William, Arik Levinson, and David Wilson. 2000. Reexamining the Empirical Evidence for an Environmental Kuznets Curve. Working Paper 7711. The Review of Economics and Statistics 84: 541-51. [CrossRef]

Heerink, Nico, Abay Mulatu, and Erwin Bulte. 2001. Income Inequality and the Environment: Aggregation Bias in Environmental Kuznets Curves. Ecological Economics 38: 359-67. [CrossRef]

Heidkamp, C. Patrick. 2008. A Theoretical Framework for a 'Spatially Conscious' Economic Analysis of Environmental Issues. Geoforum 39: 62-75. [CrossRef]

Hill, Robert J., and Elisabetta Magnani. 2002. An Exploration of the Conceptual and Empirical Basis of the Environmental Kuznets Curve. Australian Economic Papers 41: 239-54. [CrossRef]

Incerti, G., E. Feoli, L. Salvati, A. Brunetti, and A. Giovacchini. 2007. Analysis of Bioclimatic Time Series and Their Neural Network-Based Classification to Characterise Drought Risk Patterns in South Italy. International Journal of Biometeorology 51: 253-63. [CrossRef] [PubMed]

Jaffe, Adam B., Richard G. Newell, and Robert N. Stavins. 2005. A Tale of Two Market Failures: Technology and Environmental Policy. Ecological Economics 54: 164-74. [CrossRef]

James, Alexander N. 1999. Agricultural Land Use and Economic Growth: Environmental Implications of the Kuznets Curve. International Journal of Sustainable Development 2: 530-53. [CrossRef]

Jha, Raghbendra, and K. V. Bhanu Murthy. 2003. An Inverse Global Environmental Kuznets Curve. Journal of Comparative Economics 31: 352-68. [CrossRef]

Kahuthu, A. 2006. Economic Growth and Environmental Degradation in a Global Context. Environment, Development and Sustainability 8: 55-68. [CrossRef]

Kaika, Dimitra, and Efthimios Zervas. 2013a. The Environmental Kuznets Curve (EKC) Theory. Part B: Critical Issues. Energy Policy 62: 1403-11. [CrossRef]

Kaika, Dimitra, and Efthimios Zervas. 2013b. The Environmental Kuznets Curve (EKC) Theory-Part A: Concept, Causes and the $\mathrm{CO}_{2}$ Emissions Case. Energy Policy 62: 1392-402. [CrossRef]

Kairis, O., C. Karavitis, A. Kounalaki, L. Salvati, and C. Kosmas. 2013. The Effect of Land Management Practices on Soil Erosion and Land Desertification in an Olive Grove. Soil Use and Management 29: 597-606. [CrossRef]

Kairis, Orestis, Christos Karavitis, Luca Salvati, Aikaterini Kounalaki, and Kostas Kosmas. 2015. Exploring the Impact of Overgrazing on Soil Erosion and Land Degradation in a Dry Mediterranean Agro-Forest Landscape (Crete, Greece). Arid Land Research and Management 29: 360-74. [CrossRef]

Karamesouti, M., V. Detsis, A. Kounalaki, P. Vasiliou, L. Salvati, and C. Kosmas. 2015. Land-Use and Land Degradation Processes Affecting Soil Resources: Evidence from a Traditional Mediterranean Cropland (Greece). Catena 132: 45-55. [CrossRef]

Katircioğlu, Setareh, and Salih Katircioğlu. 2018. Testing the role of urban development in the conventional Environmental Kuznets Curve: Evidence from Turkey. Applied Economics Letters 25: 741-46. [CrossRef]

Kazemzadeh-Zow, Ali, Saeed Zanganeh Shahraki, Luca Salvati, and Najmeh Neisani Samani. 2017. A spatial zoning approach to calibrate and validate urban growth models. International Journal of Geographical Information Science 31: 763-82. [CrossRef]

Kim, Yoomi, Katsuya Tanaka, and Chazhong Ge. 2018. Estimating the Provincial Environmental Kuznets Curve in China: A Geographically Weighted Regression Approach. Stochastic Environmental Research and Risk Assessment 32: 2147-63. [CrossRef]

Kosmas, Costas, Mina Karamesouti, Kate Kounalaki, Vassilis Detsis, Penny Vassiliou, and Luca Salvati. 2016. Land Degradation and Long-Term Changes in Agro-Pastoral Systems: An Empirical Analysis of Ecological Resilience in Asteroussia - Crete (Greece). Catena 147: 196-204. [CrossRef]

Lamonica, Giuseppe Ricciardo, and Francesco Maria Chelli. 2018. The Performance of Non-Survey Techniques for Constructing Sub-Territorial Input-Output Tables. Papers in Regional Science 97: 1169-202. [CrossRef]

Lamonica, Giuseppe R., Maria C. Recchioni, Francesco M. Chelli, and Luca Salvati. 2020. The efficiency of the cross-entropy method when estimating the technical coefficients of input-output tables. Spatial Economic Analysis 15: 62-91. [CrossRef]

Lantz, Van. 2002. Is There an Environmental Kuznets Curve for Clearcutting in Canadian Forests? Journal of Forest Economics 8: 199-212. [CrossRef]

Li, Tingting, Yong Wang, and Dingtao Zhao. 2016. Environmental Kuznets Curve in China: New Evidence from Dynamic Panel Analysis. Energy Policy 91: 138-47. [CrossRef] 
Lin, Boqiang, Oluwasola E. Omoju, Ngozi M. Nwakeze, Jennifer U. Okonkwo, and Ebenezer T. Megbowon. 2016. Is the Environmental Kuznets Curve Hypothesis a Sound Basis for Environmental Policy in Africa? Journal of Cleaner Production 133: 712-24. [CrossRef]

List, John A., and Craig A. Gallet. 1999. The Environmental Kuznets Curve: Does One Size Fit All? Ecological Economics 31: 409-23. [CrossRef]

Luzzati, Tommaso, Marco Orsini, and Gianluca Gucciardi. 2018. A Multiscale Reassessment of the Environmental Kuznets Curve for Energy and $\mathrm{CO}_{2}$ Emissions. Energy Policy 122: 612-21. [CrossRef]

Madden, Ben, Nick Florin, Steve Mohr, and Damien Giurco. 2019. Using the Waste Kuznet's Curve to Explore Regional Variation in the Decoupling of Waste Generation and Socioeconomic Indicators. Resources, Conservation, and Recycling 49: 674-86. [CrossRef]

Maddison, David. 2006. Environmental Kuznets Curves: A Spatial Econometric Approach. Journal of Environmental Economics and Management 51: 218-30. [CrossRef]

Maddison, David. 2007. Modelling Sulphur Emissions in Europe: A Spatial Econometric Approach. Oxford Economic Papers 59: 726-43. [CrossRef]

Magnani, Elisabetta. 2000. The Environmental Kuznets Curve, Environmental Protection Policy and Income Distribution. Ecological Economics 32: 431-43. [CrossRef]

Magnani, Elisabetta. 2001. The Environmental Kuznets Curve: Development Path or Policy Result? Environmental Modelling \& Software 16: 157-65. [CrossRef]

Marston, Sallie A, John Paul Jones III, and Keith Woodward. 2005. Human geography without scale. Transactions of the Institute of British Geographers 30: 416-32. [CrossRef]

Mazzanti, Massimiliano, Anna Montini, and Roberto Zoboli. 2008. Environmental Kuznets Curves for Air Pollutant Emissions in Italy: Evidence from Environmental Accounts (NAMEA) Panel Data. Economic Systems Research 20: 277-301. [CrossRef]

Mukherjee, Sacchidananda, and Vinish Kathuria. 2006. Is Economic Growth Sustainable? Environmental Quality of Indian States Post 1991. SSRN Scholarly Paper ID 1020544. Rochester: Social Science Research Network.

Müller-Fürstenberger, Georg, and Martin Wagner. 2007. Exploring the Environmental Kuznets Hypothesis: Theoretical and Econometric Problems. Ecological Economics 62: 648-60. [CrossRef]

Munasinghe, Mohan. 1999. Is Environmental Degradation an Inevitable Consequence of Economic Growth: Tunneling through the Environmental Kuznets Curve. Ecological Economics 29: 89-109. [CrossRef]

Nijkamp, P. 1999. Environmental and Regional Economics. Cheltenham: Edward Elgar Publishing.

North, Peter. 2005. Scaling Alternative Economic Practices? BlackwellPublishing, Ltd. Some Lessons from Alternative Currencies. Transactions of the Institute of British Geographers 30: 221-33. [CrossRef]

Özokcu, Selin, and Özlem Özdemir. 2017. Economic Growth, Energy, and Environmental Kuznets Curve. Renewable and Sustainable Energy Reviews 72: 639-47. [CrossRef]

Ozturk, Ilhan, Usama Al-Mulali, and Behnaz Saboori. 2016. Investigating the Environmental Kuznets Curve Hypothesis: The Role of Tourism and Ecological Footprint. Environmental Science and Pollution Research 23: 1916-28. [CrossRef]

Panayotou, Theodore. 1997. Demystifying the Environmental Kuznets Curve: Turning a Black Box into a Policy Tool. Environment and Development Economics 2: 465-84. [CrossRef]

Paudel, Krishna P., Hector Zapata, and Dwi Susanto. 2005. An Empirical Test of Environmental Kuznets Curve for Water Pollution. Environmental and Resource Economics 31: 325-48. [CrossRef]

Ranjan, Ram, and James Shortle. 2007. The Environmental Kuznets Curve When the Environment Exhibits Hysteresis. Ecological Economics 64: 204-15. [CrossRef]

Rasli, Amran Md., Muhammad Imran Qureshi, Aliyu Isah-Chikaji, Khalid Zaman, and Mehboob Ahmad. 2018. New Toxics, Race to the Bottom and Revised Environmental Kuznets Curve: The Case of Local and Global Pollutants. Renewable and Sustainable Energy Reviews 81: 3120-30. [CrossRef]

Recanatesi, Fabio, Matteo Clemente, Efstathios Grigoriadis, Flavia Ranalli, Marco Zitti, and Luca Salvati. 2016. A Fifty-Year Sustainability Assessment of Italian Agro-Forest Districts. Sustainability 8: 32. [CrossRef]

Rehman, Faiz Ur, Muhammad Nasir, and Faiza Kanwal. 2012. Nexus between Corruption and Regional Environmental Kuznets Curve: The Case of South Asian Countries. Environment, Development and Sustainability 14: 827-41. [CrossRef]

Rodrigo-Comino, Jesús, José María Senciales, Artemi Cerdà, and Eric C. Brevik. 2018. The multidisciplinary origin of soil geography: A review. Earth-Science Reviews 177: 114-23. [CrossRef] 
Rontos, Kostas, Efstathios Grigoriadis, Adele Sateriano, Maria Syrmali, Ioannis Vavouras, and Luca Salvati. 2016. Lost in Protest, Found in Segregation: Divided Cities in the Light of the 2015 "Oxı" Referendum in Greece. City, Culture and Society 7: 139-48. [CrossRef]

Rosti, Luisa, and Francesco Chelli. 2009. Self-employment among Italian Female Graduates. Education + Training 51: 526-40. [CrossRef]

Rosti, Luisa, and Francesco Chelli. 2012. Higher Education in Non-standard Wage Contracts. Education + Training 54: 142-51. [CrossRef]

Rosti, Luisa, Chikara Yamaguchi, and Carolina Castagnetti. 2005. Educational Performance as Signalling Device: Evidence from Italy. Economics Bulletin 9: 1-7.

Rupasingha, Anil, Stephan J. Goetz, David L. Debertin, and Angelos Pagoulatos. 2004. The Environmental Kuznets Curve for US Counties: A Spatial Econometric Analysis with Extensions*. Papers in Regional Science 83: 407-24. [CrossRef]

Salvati, Luca. 2014. A Socioeconomic Profile of Vulnerable Land to Desertification in Italy. The Science of the Total Environment 466-467: 287-99. [CrossRef]

Salvati, Luca. 2016. The Dark Side of the Crisis: Disparities in per Capita Income (2000-2012) and the Urban-Rural Gradient in Greece. Tijdschrift Voor Economische En Sociale Geografie 107: 628-41. [CrossRef]

Salvati, Luca, and Margherita Carlucci. 2010. Estimating Land Degradation Risk for Agriculture in Italy Using an Indirect Approach. Ecological Economics 69: 511-18. [CrossRef]

Salvati, Luca, and Pere Serra. 2016. Estimating Rapidity of Change in Complex Urban Systems: A Multidimensional, Local-Scale Approach. Geographical Analysis 48: 132-56. [CrossRef]

Salvati, Luca, and Marco Zitti. 2005. Land degradation in the Mediterranean basin: Linking bio-physical and economic factors into an ecological perspective. Biota 5: 67-77.

Salvati, Luca, and Marco Zitti. 2008. Regional Convergence of Environmental Variables: Empirical Evidences from Land Degradation. Ecological Economics 68: 162-68. [CrossRef]

Salvati, Luca, and Marco Zitti. 2009a. Substitutability and Weighting of Ecological and Economic Indicators: Exploring the Importance of Various Components of a Synthetic Index. Ecological Economics 68: 1093-99. [CrossRef]

Salvati, Luca, and Marco Zitti. 2009b. Assessing the Impact of Ecological and Economic Factors on Land Degradation Vulnerability through Multiway Analysis. Ecological Indicators 9: 357-63. [CrossRef]

Salvati, Luca, and Marco Zitti. 2009c. The Environmental “Risky" Region: Identifying Land Degradation Processes Through Integration of Socio-Economic and Ecological Indicators in a Multivariate Regionalization Model. Environmental Management 44: 888. [CrossRef]

Salvati, Luca, Alberto Mancini, Sofia Bajocco, Roberta Gemmiti, and Margherita Carlucci. 2011. Socioeconomic Development and Vulnerability to Land Degradation in Italy. Regional Environmental Change 11: 767-77. [CrossRef]

Salvati, Luca, Roberta Gemmiti, and Luigi Perini. 2012. Land degradation in Mediterranean urban areas: An unexplored link with planning? Area 44: 317-25. [CrossRef]

Salvati, Luca, Marco Zitti, and Luigi Perini. 2016. Fifty Years on: Long-Term Patterns of Land Sensitivity to Desertification in Italy. Land Degradation \& Development 27: 97-107. [CrossRef]

Sannigrahi, S., P. K. Joshi, S. Keesstra, S. K. Paul, S. Sen, P. S. Roy, S. Chakraborti, and S. Bhatt. 2019. Evaluating landscape capacity to provide spatially explicit valued ecosystem services for sustainable coastal resource management. Ocean and Coastal Management 182. [CrossRef]

Sannigrahi, Srikanta, Qi Zhang, Francesco Pilla, Pawan Kumar Joshi, Bidroha Basu, Saskia Keesstra, P. S. Roy, Ying Wang, Paul C. Sutton, Suman Chakraborti, and et al. 2020. Responses of ecosystem services to natural and anthropogenic forcings: A spatial regression based assessment in the world's largest mangrove ecosystem. Science of the Total Environment 715. [CrossRef] [PubMed]

Scarascia, M. E. Venezian, F. Di Battista, and L. Salvati. 2006. Water Resources in Italy: Availability and Agricultural Uses. Irrigation and Drainage 55: 115-27. [CrossRef]

Smiraglia, D., T. Ceccarelli, S. Bajocco, L. Salvati, and L. Perini. 2016. Linking Trajectories of Land Change, Land Degradation Processes and Ecosystem Services. Environmental Research 147: 590-600. [CrossRef] [PubMed]

Smulders, J. A. 1999. Endogenous Growth Theory and the Environment. In Handbook of Environmental and Resource Economics. Amsterdam: Edward Elgar Publishing, pp. 610-21. 
Sobhee, Sanjeev K. 2004. The environmental Kuznets curve (EKC): A logistic curve? Applied Economics Letters 11: 449-52. [CrossRef]

Spangenberg, Joachim H. 2001. The Environmental Kuznets Curve: A Methodological Artefact? Population and Environment 23: 175-91. [CrossRef]

Stern, David I. 1998. Progress on the Environmental Kuznets Curve? Environment and Development Economics 3: 173-96. [CrossRef]

Stern, David I. 2004. The Rise and Fall of the Environmental Kuznets Curve. World Development 32: 1419-39. [CrossRef]

Tan, Xiaomei. 2006. Environment, Governance and GDP: Discovering Their Connections. International Journal of Sustainable Development 9: 311. [CrossRef]

Vincent, Jeffrey R. 1997. Testing for Environmental Kuznets Curves within a Developing Country. Environment and Development Economics 2: 417-31. [CrossRef]

Wang, Pingo, Alok K. Bohara, Robert P. Berrens, and Kishore Gawande. 1998. A risk-based environmental Kuznets curve for US hazardous waste sites. Applied Economics Letters 5: 761-63. [CrossRef]

Xie, Qichang, Xin Xu, and Xiaqing Liu. 2019. Is There an EKC between Economic Growth and Smog Pollution in China? New Evidence from Semiparametric Spatial Autoregressive Models. Journal of Cleaner Production 220: 873-83. [CrossRef]

Yamamoto, Daisaku. 2008. Scales of Regional Income Disparities in the USA, 1955-2003. Journal of Economic Geography 8: 79-103. [CrossRef]

Zaim, Osman, and Fatma Taskin. 2000. A Kuznets Curve in Environmental Efficiency: An Application on OECD Countries. Environmental and Resource Economics 17: 21-36. [CrossRef]

Zaman, Khalid, Muhammad Shahbaz, Nanthakumar Loganathan, and Syed Ali Raza. 2016. Tourism Development, Energy Consumption and Environmental Kuznets Curve: Trivariate Analysis in the Panel of Developed and Developing Countries. Tourism Management 54: 275-83. [CrossRef]

Zoundi, Zakaria. 2017. $\mathrm{CO}_{2}$ Emissions, Renewable Energy and the Environmental Kuznets Curve, a Panel Cointegration Approach. Renewable and Sustainable Energy Reviews 72: 1067-75. [CrossRef]

Zuindeau, Bertrand. 2007. Territorial Equity and Sustainable Development. Environmental Values 16: $253-68$. [CrossRef]

(C) 2020 by the authors. Licensee MDPI, Basel, Switzerland. This article is an open access article distributed under the terms and conditions of the Creative Commons Attribution (CC BY) license (http://creativecommons.org/licenses/by/4.0/). 